\title{
Outpatient Gatifloxacin Therapy and Dysglycemia in Older Adults
}

\author{
Laura Y. Park-Wyllie, Pharm.D., David N. Juurlink, M.D., Ph.D., \\ Alexander Kopp, B.A., Baiju R. Shah, M.D., Ph.D., Therese A. Stukel, Ph.D., \\ Carmine Stumpo, Pharm.D., Linda Dresser, Pharm.D., Donald E. Low, M.D., \\ and Muhammad M. Mamdani, Pharm.D., M.P.H.
}

\section{A BSTRACT}

From the Institute for Clinical Evaluative Sciences (L.Y.P.-W., D.N.J., A.K., B.R.S., T.A.S., M.M.M.); the Centre for Research on Inner City Health, Department of Family and Community Medicine, St. Michael's Hospital (L.Y.P.-W.); the Department of Medicine and the Clinical Epidemiology Unit, Sunnybrook and Women's College Health Sciences Centre (D.N.J., B.R.S.) the Departments of Pediatrics (D.N.J.) Medicine (D.N.J., B.R.S.), Health Policy, Management, and Evaluation (D.N.J. T.A.S., M.M.M.), Pharmacy (L.D., M.M.M.) and Microbiology (D.E.L.), University of Toronto; the Department of Pharmacy, Toronto East General Hospital (C.S.); the Department of Pharmacy, Mount Sinai Hospital (L.D.); and the Department of Microbiology, University Health Network-Mount Sinai Hospital (D.E.L.) all in Toronto. Address reprint requests to Dr. Juurlink at Sunnybrook and Women's College Health Sciences Centre 2075 Bayview Ave., G Wing 106, Toronto, ON M4N 3M5, Canada, or at dnj@ices. on.ca.

This article was published at www.nejm org on March 1, 2006.

N Engl J Med 2006;354:1352-61. Copyright $(2006$ Massachusetts Medical Society.

\section{BACKGROUND}

Gatifloxacin has been associated with both hypoglycemia and hyperglycemia. We examined dysglycemia-related health outcomes associated with various antibiotics in a population of approximately 1.4 million Ontario, Canada, residents 66 years of age or older.

\section{METHODS}

We conducted two population-based, nested case-control studies. In the first, case patients were persons treated in the hospital for hypoglycemia after outpatient treatment with a macrolide, a second-generation cephalosporin, or a respiratory fluoroquinolone (gatifloxacin, levofloxacin, moxifloxacin, or ciprofloxacin). In the second, case patients were persons who received hospital care for hyperglycemia. For each case patient, we identified up to five controls matched according to age, sex, the presence or absence of diabetes, and the timing of antibiotic therapy.

\section{RESULTS}

Between April 2002 and March 2004, we identified 788 patients treated for hypoglycemia within 30 days after antibiotic therapy. As compared with macrolide antibiotics, gatifloxacin was associated with an increased risk of hypoglycemia (adjusted odds ratio, 4.3; 95 percent confidence interval, 2.9 to 6.3). Levofloxacin was also associated with a slightly increased risk (adjusted odds ratio, 1.5; 95 percent confidence interval, 1.2 to 2.0), but no such risk was seen with moxifloxacin, ciprofloxacin, or cephalosporins. We then identified 470 patients treated for hyperglycemia within 30 days after antibiotic therapy. As compared with macrolides, gatifloxacin was associated with a considerably increased risk of hyperglycemia (adjusted odds ratio, 16.7; 95 percent confidence interval, 10.4 to 26.8), but no risk was noted with the other antibiotics. Risks were similar in the two studies regardless of the presence or absence of diabetes.

\section{CONCLUSIONS}

As compared with the use of other broad-spectrum oral antibiotics, including other fluoroquinolones, the use of gatifloxacin among outpatients is associated with an increased risk of in-hospital treatment for both hypoglycemia and hyperglycemia. 
$\mathrm{F}$ LUOROQUINOLONES, BROAD-SPECTRUM antibiotics that are widely perceived to have favorable adverse-effect profiles, have become the most prescribed antibiotics in the United States. ${ }^{1}$ From 1995 to 2002, the number of fluoroquinolone prescriptions in the United States increased by a factor of more than three, reaching about 22 million prescriptions per year. ${ }^{1}$

The available fluoroquinolones have wellestablished differences in antimicrobial activity, but their disparate adverse-effect profiles are increasingly being recognized. Serious adverse events have led to the withdrawal or restriction of several fluoroquinolones in recent years, ${ }^{2}$ including temafloxacin (because of hemolysis, renal failure, and hypoglycemia), ${ }^{3,4}$ grepafloxacin and sparfloxacin (because of QT-interval prolongation), ${ }^{4-6}$ and trovafloxacin (because of hepatotoxicity). ${ }^{6,7}$

Limited data suggest that as compared with other currently available fluoroquinolones, gatifloxacin (Tequin, Bristol-Myers Squibb) may be uniquely associated with increased risks of both hypoglycemia and hyperglycemia..$^{8-26}$ Although the mechanism of these apparently competing adverse effects is not fully understood, studies in animals suggest that although gatifloxacin can promote insulin release and hypoglycemia by blocking the ATP-sensitive potassium channels of pancreatic islet cells, it can also trigger the vacuolation of pancreatic beta cells, leading to reduced insulin levels and hyperglycemia. , $^{90,24,27,28}$

Evidence that gatifloxacin causes dysglycemic effects in humans consists of data from case reports, small studies in healthy volunteers or hospital inpatients, and one small post-marketing study. ${ }^{25,29-34}$ These studies yielded conflicting conclusions regarding the effects of gatifloxacin on blood glucose levels, but some reports strongly suggest the existence of a causal relation. ${ }^{26}$ For example, one recent report described two patients in whom profound hyperglycemia (glucose, 942 to $1456 \mathrm{mg}$ per deciliter [52 to $81 \mathrm{mmol}$ per liter]) developed shortly after gatifloxacin therapy but who had no subsequent evidence of diabetes. ${ }^{26}$

Given the popularity of fluoroquinolones and the potentially life-threatening consequences of dysglycemia, we conducted two nested casecontrol studies in patients treated with broadspectrum antibiotics identified on the basis of the health care records. We examined the records of more than 1.4 million residents of Ontario, Canada, who were at least 66 years old. Our aim was to explore the association between antibiotic use and subsequent hospital visits for hypoglycemia or hyperglycemia. We hypothesized that gatifloxacin would be more strongly associated with these outcomes than would other broad-spectrum antibiotics, including other commonly used fluoroquinolones.

METHODS

\section{SETTING AND DESIGN}

We used a nested case-control design to examine drug use and clinical outcomes within a cohort of Ontario outpatients 66 years of age or older ${ }^{35-38}$ who had received broad-spectrum antibiotics that are often used for the treatment of lower respiratory tract infections. These persons receive universal access to hospital care, physicians' services, and prescription-drug coverage. The study was approved by the research ethics board of Sunnybrook and Women's College Health Sciences Centre. Consent was not required, given the study methods and the masking of the patients' identities.

\section{SOURCES OF DATA}

We identified prescription records using the Ontario Drug Benefit database, which contains comprehensive records of prescription medications dispensed to Ontario residents 65 years of age or older. ${ }^{39}$ Hospital visits were identified with use of the National Ambulatory Care Reporting System database and the Canadian Institute for Health Information Discharge Abstract Database, which contain detailed diagnostic and procedural information regarding emergency department visits and hospital admissions, respectively.

We used the Ontario Health Insurance Plan database to identify claims for inpatient and outpatient physician services. Basic demographic information was obtained from the Registered Persons Database, a registry containing a single, unique record for all Ontario residents ever issued a health card. Socioeconomic status was estimated for each patient by linking the home postal code to Statistics Canada population census data to obtain the median household-income quintile. ${ }^{40-43}$ These databases have little missing information and were linked in an anonymous fashion with the use of encrypted individual health-card numbers, as in previous studies..$^{35,36,44,45}$ 


\section{CASE PATIENTS AND CONTROLS}

In the first study, we defined case patients as persons who received hospital care (emergency department treatment or hospital admission) for hypoglycemia within 30 days after receiving a prescription for a macrolide (erythromycin, clarithromycin, or azithromycin) an oral second-generation cephalosporin (cefuroxime axetil or cefaclor), or a respiratory fluoroquinolone (gatifloxacin, levofloxacin, moxifloxacin, or ciprofloxacin). Persons admitted for hypoglycemia between April 1, 2002, and March 31, 2004, were included as case patients in the study.

Hospital visits for hypoglycemia were identified with use of codes from the International Statistical Classification of Diseases and Related Health Problems, 10th revision ${ }^{46}$ (ICD-10), for hypoglycemia (E10.63, E11.63, E13.63, E14.63, E16.1, or E16.2), hypoglycemic coma (E15), and drug-induced hypoglycemia (E16.0). We examined emergency department care in combination with hospital admissions because both are likely to signify the occurrence of serious adverse events and because admission is sometimes discretionary and can be influenced by nonmedical factors, particularly among older patients.

The date of hospital treatment served as the reference date in all analyses. Only the first hospital visit for hypoglycemia was considered in the instance of patients who had multiple episodes during the study period. Patients who received antibiotics from more than one class during the 30 days before the reference date were excluded from the analysis. We excluded patients hospitalized within 90 days before the reference date to avoid the potentially confounding effects of recent illness and also excluded patients during their first year of eligibility for prescription-drug coverage (which begins at the age of 65 years) to avoid incomplete medication records.

For each case patient, we randomly selected up to five controls from the population of patients who had received antibiotics but who did not receive care for hypoglycemia in the hospital. Controls were assigned the same reference date as their corresponding case patient and were required to have received one of the antibiotics listed above during the preceding 30 days; thus, all case patients and controls were nested within a cohort of outpatients recently treated with broad-spectrum antibiotics. Controls were also matched to case patients according to age (birth within one year of the case patient), sex, and the presence or absence of diabetes, defined as any prescription for insulin or glucose-lowering drugs during the previous six months. Because we anticipated that antibiotic-associated hypoglycemia would be a time-dependent phenomenon, we also matched case patients and controls according to the time (in days) from the initiation of antibiotic therapy to the reference date. When fewer than five controls could be matched to a case patient, we used only those controls and did not alter the matching algorithm.

In the second study, case patients were defined as persons hospitalized with any diagnosis of hyperglycemia (ICD-10 code R73.9), diabetic ketoacidosis (E10.10, E10.12, E11.10, E11.12, E13.10, E13.12, E14.10, or E14.12), or hyperosmolar nonketotic coma (E11.00, E11.01, E13.00, E13.01, E14.00, or E14.01) after outpatient treatment with a macrolide, a second-generation cephalosporin, or a respiratory fluoroquinolone during the previous 30 days. Otherwise, the design and analysis were identical to those described above.

\section{STATISTICAL ANALYSIS}

The primary analysis examined the association between outpatient use of gatifloxacin and subsequent hospital treatment for hypoglycemia (in the first study) or hyperglycemia (in the second). To place our findings in context, we conducted similar analyses for levofloxacin, moxifloxacin, ciprofloxacin, and the second-generation cephalosporins as a group.

Because any serious infection could be associated with hospitalization involving alterations in blood glucose levels, we used macrolide antibiotics as the reference group in all analyses. Macrolides and respiratory fluoroquinolones are prescribed for similar community-acquired infections, but macrolides do not directly influence glycemic control.

Conditional logistic regression was used to estimate odds ratios and 95 percent confidence intervals for the association between hypoglycemic events and recent antibiotic use. In the multivariable analysis, we adjusted for conditions that might influence or be reflective of glycemic control, including liver disease, renal insufficiency, and alcohol abuse, as well as the number of hospital admissions involving dysglycemia during the preceding two years, the number of hospitalizations for any reason during the preceding year, 
and the number of days during the previous year on which there was a visit to an endocrinologist, internist, or family physician. We also adjusted for recent prescriptions (within the preceding 180 days) for insulin, oral hypoglycemic agents, or other drugs that might influence glycemic control (a more complete description is provided in the Supplementary Appendix, available with the full text of this article at www.nejm.org). ${ }^{47,48}$ Because the pharmacokinetics of sulfonylurea hypoglycemic agents can be influenced by drugs that modulate the activity of cytochrome P-450 isoenzyme $2 \mathrm{C} 9,{ }^{37}$ we adjusted for the receipt of commonly used inhibitors and inducers of this enzyme (see the Supplementary Appendix). Finally, we adjusted for socioeconomic status and for the number of drugs received during the previous year, which is a validated index of comorbidity among ambulatory patients..$^{49-52}$

We performed stratified analyses among patients with and those without diabetes. All analyses used a two-sided type I error rate of 0.05 as the threshold for statistical significance and were performed with the use of SAS software (version 8.2, SAS Institute).

\section{RESULTS}

\section{HYPOGLYCEMIA}

During the two-year study period, we identified 788 patients who received hospital care for hypoglycemia within 30 days after outpatient antibiotic therapy. Of these patients, 93.4 percent were matched to five controls. Most case patients (91.9 percent) were being treated for diabetes. The characteristics of the case patients and the controls are shown in Table 1 . Their mean $( \pm S D)$ age was $78.0 \pm 6.8$ years, and 1950 (42.6 percent) were male. The median time from the initiation of antibiotic therapy to treatment in the hospital was 6 days (interquartile range, 2 to 15). Slightly more than half the case patients (422 [53.6 percent]) were released from the emergency department after treatment. Among the 366 case patients who were admitted to the hospital, the median length of stay was 7 days (interquartile range, 3 to 14), and 30 (8.1 percent) died before discharge.

Patients treated for hypoglycemia were more than four times as likely as controls to have recently been treated with gatifloxacin as compared with a macrolide antibiotic (adjusted odds ratio, 4.3; 95 percent confidence interval, 2.9 to 6.3 )
(Table 2). We also observed a significant but weaker association between hypoglycemia and levofloxacin (adjusted odds ratio, 1.5; 95 percent confidence interval, 1.2 to 2.0). In contrast, we found no increased risk of hypoglycemia after treatment with either moxifloxacin or ciprofloxacin. As expected, we also observed no association between hypoglycemia and second-generation cephalosporins.

Similar findings were observed in analyses stratified according to drug treatment for diabetes (Table 2). The association between gatifloxacin and hypoglycemia was highest among patients who were not receiving therapy for diabetes (adjusted odds ratio, 9.0; 95 percent confidence interval, 1.3 to 63.4), although this observation was based on relatively few cases (64). The findings were similar when we restricted the analysis to patients who were admitted to the hospital.

\section{HYPERGLYCEMIA}

We identified 470 case patients who made hyperglycemia-related hospital visits after outpatient antibiotic therapy. Of these patients, 94.9 percent were matched to five controls. More than a third of them (178 [37.9 percent]) had not received treatment for diabetes within 180 days before receiving care in the hospital. The characteristics of the case patients and the controls are shown in Table 1. Their mean age was 77.4 \pm 7.4 years, and 1194 (43.4 percent) were male. The median time from the initiation of antibiotic therapy to treatment in the hospital was 5 days (interquartile range, 2 to 13). Half the case patients (233 [49.6 percent]) were treated and released from the emergency department. Of the 237 patients who were admitted to the hospital, the median length of stay was 9 days (interquartile range, 5 to 14), and 39 (16.5 percent) died before discharge.

Patients treated in the hospital for hyperglycemia were almost 17 times as likely as controls to have recently been treated with gatifloxacin as compared with a macrolide antibiotic (adjusted odds ratio, 16.7; 95 percent confidence interval, 10.4 to 26.8) (Table 3). In contrast, we found no evidence of an increased risk of hyperglycemia with any other fluoroquinolone or with the second-generation cephalosporins.

The findings were similar in analyses stratified according to the presence or absence of diabetes. The association between gatifloxacin and hyperglycemia was highest among patients treat- 


\begin{tabular}{|c|c|c|c|c|}
\hline \multirow[t]{2}{*}{ Characteristic } & \multicolumn{2}{|c|}{ Hypoglycemia } & \multicolumn{2}{|c|}{ Hyperglycemia } \\
\hline & $\begin{array}{l}\text { Case Patients } \\
\qquad(\mathrm{N}=788)\end{array}$ & $\begin{array}{l}\text { Controls } \\
(\mathrm{N}=3791)\end{array}$ & $\begin{array}{l}\text { Case Patients } \\
\qquad(\mathrm{N}=470)\end{array}$ & $\begin{array}{l}\text { Controls } \\
(\mathrm{N}=2280)\end{array}$ \\
\hline \multicolumn{5}{|l|}{ Demographic and medical characteristics } \\
\hline Age $-y r$ & $78.4 \pm 7.2$ & $77.8 \pm 6.7$ & $77.8 \pm 7.2$ & $77.3 \pm 6.7$ \\
\hline Male sex — no. (\%) & $338(42.9)$ & $1612(42.5)$ & $204(43.4)$ & $990(43.4)$ \\
\hline \multicolumn{5}{|l|}{$\begin{array}{l}\text { Interval from start of antibiotic therapy to } \\
\text { in-hospital treatment — days }\end{array}$} \\
\hline Median & 6 & 6 & 5 & 6 \\
\hline Interquartile range & $2-15$ & $2-15$ & $2-13$ & $2-13$ \\
\hline $\begin{array}{l}\text { Residence in a long-term care facility - } \\
\text { no. (\%) }\end{array}$ & $142(18.0)$ & $505(13.3)$ & $101(21.5)$ & $289(12.7)$ \\
\hline \multicolumn{5}{|l|}{ Socioeconomic status - no. (\%) } \\
\hline 1 (lowest) & $201(25.5)$ & $875(23.1)$ & $111(23.6)$ & $517(22.7)$ \\
\hline 2 & $200(25.4)$ & $874(23.1)$ & $126(26.8)$ & $517(22.7)$ \\
\hline 3 & $136(17.3)$ & 717 (18.9) & $73(15.5)$ & $438(19.2)$ \\
\hline 4 & $119(15.1)$ & $652(17.2)$ & $76(16.2)$ & $383(16.8)$ \\
\hline 5 (highest) & $102(12.9)$ & $549(14.5)$ & $70(14.9)$ & $341(15.0)$ \\
\hline Data missing & $30(3.8)$ & $124(3.3)$ & $14(3.0)$ & $84(3.7)$ \\
\hline \multicolumn{5}{|l|}{ No. of visits during preceding year } \\
\hline To a family physician & $17.0 \pm 14.5$ & $15.3 \pm 12.9$ & $17.6 \pm 15.2$ & $14.7 \pm 12.8$ \\
\hline To a general internist & $0.8 \pm 2.1$ & $0.6 \pm 2.2$ & $0.5 \pm 1.8$ & $0.7 \pm 1.7$ \\
\hline To an endocrinologist & $0.3 \pm 1.0$ & $0.3 \pm 0.9$ & $0.2 \pm 0.6$ & $0.2 \pm 0.7$ \\
\hline Renal dysfunction — no. (\%) & $75(9.5)$ & $200(5.3)$ & $30(6.4)$ & $87(3.8)$ \\
\hline Liver disease — no. (\%) & $7(0.9)$ & $24(0.6)$ & $<6$ & $15(0.7)$ \\
\hline Alcohol abuse — no. (\%) & $11(1.4)$ & $38(1.0)$ & $<6$ & $25(1.1)$ \\
\hline $\begin{array}{l}\text { Hypoglycemia-related hospitalization during } \\
\text { preceding } 2 \text { yr - no. (\%) }\end{array}$ & $19(2.4)$ & $21(0.6)$ & $<6$ & $10(0.4)$ \\
\hline $\begin{array}{l}\text { Hyperglycemia-related hospitalization during } \\
\text { preceding } 2 \text { yr - no. (\%) }\end{array}$ & $<6$ & $7(0.2)$ & $<6$ & $<6$ \\
\hline No. of hospitalizations during preceding year & $0.5 \pm 0.8$ & $0.3 \pm 0.8$ & $0.5 \pm 1.0$ & $0.3 \pm 0.7$ \\
\hline \multicolumn{5}{|l|}{ Drug therapy } \\
\hline \multicolumn{5}{|l|}{ Oral glucose-lowering agents — no. (\%) } \\
\hline Biguanides & $372(47.2)$ & $1979(52.2)$ & $160(34.0)$ & $837(36.7)$ \\
\hline Thiazolidinediones & $24(3.0)$ & $101(2.7)$ & $12(2.6)$ & $40(1.8)$ \\
\hline Acarbose & $18(2.3)$ & $74(2.0)$ & $<6$ & $27(1.2)$ \\
\hline Sulfonylureas & $491(62.3)$ & $1866(49.2)$ & $174(37.0)$ & $748(32.8)$ \\
\hline Repaglinide & $<6$ & $8(0.2)$ & $<6$ & $6(0.3)$ \\
\hline Insulin preparations - no. (\%) & $259(32.9)$ & $880(23.2)$ & $105(22.3)$ & $355(15.6)$ \\
\hline Other hyperglycemic agents — no. (\%) & $455(57.7)$ & $1997(52.7)$ & $292(62.1)$ & $1149(50.4)$ \\
\hline Cytochrome P-450 2C9 inducers - no. (\%) & $11(1.4)$ & $27(0.7)$ & $13(2.8)$ & $21(0.9)$ \\
\hline Cytochrome P-450 2C9 inhibitors - no. (\%) & $139(17.6)$ & $533(14.1)$ & $85(18.1)$ & $321(14.1)$ \\
\hline Miscellaneous medications - no. (\%) & $68(8.6)$ & $263(6.9)$ & $27(5.7)$ & $114(5.0)$ \\
\hline
\end{tabular}




\begin{tabular}{|c|c|c|c|c|}
\hline Variable & Case Patients & Controls & $\begin{array}{l}\text { Univariate Odds Ratio } \\
\qquad(95 \% \mathrm{Cl})\end{array}$ & $\begin{array}{l}\text { Adjusted Odds Ratio } \\
(95 \% \mathrm{Cl})\end{array}$ \\
\hline \multicolumn{5}{|c|}{ no. (\%) } \\
\hline All patients & 788 & 3791 & & \\
\hline \multicolumn{5}{|l|}{ Fluoroquinolones } \\
\hline Gatifloxacin & $61(7.7)$ & $77(2.0)$ & $4.4(3.0-6.3)$ & $4.3(2.9-6.3)$ \\
\hline Levofloxacin & $114(14.5)$ & $341(9.0)$ & $1.7(1.4-2.2)$ & $1.5(1.2-2.0)$ \\
\hline Moxifloxacin & $24(3.0)$ & $162(4.3)$ & $0.8(0.5-1.3)$ & $0.8(0.5-1.3)$ \\
\hline Ciprofloxacin & $209(26.5)$ & $1075(28.4)$ & $1.1(0.9-1.3)$ & $0.9(0.8-1.1)$ \\
\hline Cephalosporins广 & $62(7.9)$ & $397(10.5)$ & $0.9(0.6-1.2)$ & $0.9(0.6-1.2)$ \\
\hline Macrolides & $318(40.4)$ & $1739(45.9)$ & 1.0 & 1.0 \\
\hline Patients with diabetes & 724 & 3473 & & \\
\hline \multicolumn{5}{|l|}{ Fluoroquinolones } \\
\hline Gatifloxacin & 57 (7.9) & $73(2.1)$ & $4.3(2.9-6.2)$ & $4.2(2.8-6.3)$ \\
\hline Levofloxacin & $104(14.4)$ & $307(8.8)$ & $1.8(1.3-2.3)$ & $1.5(1.2-2.0)$ \\
\hline Moxifloxacin & $22(3.0)$ & $149(4.3)$ & $0.8(0.5-1.3)$ & $0.8(0.5-1.3)$ \\
\hline Ciprofloxacin & 195 (26.9) & $1002(28.9)$ & $1.1(0.9-1.3)$ & $0.9(0.7-1.1)$ \\
\hline Cephalosporins† & $55(7.6)$ & $362(10.4)$ & $0.8(0.6-1.1)$ & $0.8(0.6-1.1)$ \\
\hline Macrolidesł & $291(40.2)$ & $1580(45.5)$ & 1.0 & 1.0 \\
\hline Patients without diabetes & 64 & 318 & & \\
\hline \multicolumn{5}{|l|}{ Fluoroquinolones } \\
\hline Gatifloxacin & $<6$ & $<6$ & $6.4(1.4-29.9)$ & $9.0(1.3-63.4)$ \\
\hline Levofloxacin & $10(15.6)$ & $34(10.7)$ & $1.7(0.7-3.9)$ & $2.1(0.7-6.0)$ \\
\hline Moxifloxacin & $<6$ & $13(4.1)$ & $1.0(0.2-4.5)$ & $1.7(0.2-11.8)$ \\
\hline Ciprofloxacin & $14(21.9)$ & $73(23.0)$ & $1.1(0.6-2.3)$ & $1.2(0.5-2.9)$ \\
\hline Cephalosporins广 & 7 (10.9) & $35(11.0)$ & $1.2(0.5-3.0)$ & $2.3(0.8-6.7)$ \\
\hline Macrolidesł & $27(42.2)$ & $159(50.0)$ & 1.0 & 1.0 \\
\hline
\end{tabular}

* Because of rounding, not all percentages total 100. Patient numbers that are below six are not specified, in accordance with Ontario privacy regulations. $\mathrm{Cl}$ denotes confidence interval.

$\uparrow$ Cephalosporins include oral cefuroxime axetil and cefaclor.

7 Macrolides (which served as the reference group) include oral clarithromycin, azithromycin, and erythromycin.

ed with glucose-lowering drugs (adjusted odds ratio, 23.6; 95 percent confidence interval, 12.4 to 44.6), although the association remained strong among patients not receiving such treatment (adjusted odds ratio, 12.8; 95 percent confidence interval, 5.9 to 27.8). The findings were also similar when we restricted the analysis to patients who were admitted to the hospital.

\section{SUPPLEMENTARY ANALYSES}

The population-based nature of our data allowed us to estimate the incidence of dysglycemia during antibiotic therapy. We identified all patients 66 years of age or older who were treated with antibiotics during the study period. Patients hospitalized within 90 days before receiving an antibiotic prescription, as well as those who received another antibiotic prescription within 30 days, were excluded from the analysis. For each patient, we identified hospital visits for dysglycemia during the 30-day period after the start of antibiotic therapy. For patients with multiple antibiotic prescriptions during the study period, each course of treatment was considered separately. In total, 16,697 courses of gatifloxacin treatment were associated with 178 hospital visits (1.1 percent) for dysglycemia within 30 days - a rate substantially higher than the rates associated with cipro- 


\begin{tabular}{|c|c|c|c|c|}
\hline Variable & Case Patients & Controls & $\begin{array}{c}\text { Univariate Odds Ratio } \\
(95 \% \mathrm{CI})\end{array}$ & $\begin{array}{c}\text { Adjusted Odds Ratio } \\
(95 \% \mathrm{Cl})\end{array}$ \\
\hline \multicolumn{5}{|c|}{ nо. (\%) } \\
\hline All patients & 470 & 2280 & & \\
\hline \multicolumn{5}{|l|}{ Fluoroquinolones } \\
\hline Gatifloxacin & $86(18.3)$ & $42(1.8)$ & $16.3(10.4-25.4)$ & $16.7(10.4-26.8)$ \\
\hline Levofloxacin & $52(11.1)$ & $233(10.2)$ & $1.6(1.1-2.3)$ & $1.3(0.9-1.9)$ \\
\hline Moxifloxacin & $20(4.3)$ & $70(3.1)$ & $2.0(1.2-3.5)$ & $1.7(1.0-3.0)$ \\
\hline Ciprofloxacin & $113(24.0)$ & $576(25.3)$ & $1.4(1.0-1.8)$ & $1.1(0.9-1.5)$ \\
\hline Cephalosporins† & $38(8.1)$ & $235(10.3)$ & $1.2(0.8-1.7)$ & $1.2(0.8-1.7)$ \\
\hline Macrolides & $161(34.3)$ & $1124(49.3)$ & 1.0 & 1.0 \\
\hline Patients with diabetes & 292 & 1403 & & \\
\hline \multicolumn{5}{|l|}{ Fluoroquinolones } \\
\hline Gatifloxacin & $59(20.2)$ & $25(1.8)$ & $22.7(12.4-41.4)$ & $23.6(12.4-44.6)$ \\
\hline Levofloxacin & $31(10.6)$ & $129(9.2)$ & $1.9(1.2-2.9)$ & $1.6(1.0-2.5)$ \\
\hline Moxifloxacin & $9(3.1)$ & $40(2.9)$ & $2.0(0.9-4.3)$ & $1.7(0.8-3.9)$ \\
\hline Ciprofloxacin & $83(28.4)$ & $393(28.0)$ & $1.6(1.1-2.2)$ & $1.3(0.9-1.8)$ \\
\hline Cephalosporins † & $20(6.8)$ & $149(10.6)$ & $1.0(0.6-1.7)$ & $1.0(0.6-1.7)$ \\
\hline Macrolides: & $90(30.8)$ & $667(47.5)$ & 1.0 & 1.0 \\
\hline Patients without diabetes & 178 & 877 & & \\
\hline \multicolumn{5}{|l|}{ Fluoroquinolones } \\
\hline Gatifloxacin & $27(15.2)$ & 17 (1.9) & $9.9(5.0-19.5)$ & $12.8(5.9-27.8)$ \\
\hline Levofloxacin & $21(11.8)$ & 104 (11.9) & $1.4(0.8-2.3)$ & $1.0(0.5-1.8)$ \\
\hline Moxifloxacin & $11(6.2)$ & $30(3.4)$ & $2.2(1.0-4.6)$ & $1.6(0.7-3.9)$ \\
\hline Ciprofloxacin & $30(16.9)$ & $183(20.9)$ & $1.1(0.7-1.7)$ & $0.9(0.6-1.6)$ \\
\hline Cephalosporins† & $18(10.1)$ & $86(9.8)$ & $1.4(0.8-2.5)$ & $1.5(0.8-2.7)$ \\
\hline Macrolidest & 71 (39.9) & 457 (52.1) & 1.0 & 1.0 \\
\hline
\end{tabular}

* Because of rounding, not all percentages total 100. Cl denotes confidence interval.

$\dagger$ Cephalosporins include oral cefuroxime axetil and cefaclor.

Macrolides (which served as the reference group) include oral clarithromycin, azithromycin, and erythromycin.

floxacin ( 0.3 percent), levofloxacin ( 0.3 percent), moxifloxacin $(0.2$ percent), second-generation cephalosporins ( 0.2 percent), and macrolide antibiotics ( 0.1 percent).

Finally, because the product monograph for gatifloxacin (Tequin) advises the monitoring of blood glucose levels in patients with diabetes during gatifloxacin therapy, ${ }^{20}$ we looked for an interaction between gatifloxacin and diabetes. ${ }^{53} \mathrm{We}$ found no significant difference in the risk of either gatifloxacin-associated hypoglycemia or gatifloxacin-associated hyperglycemia between patients receiving treatment for diabetes and those not receiving such treatment.

\section{DISCUSSION}

In the United States, gatifloxacin has already undergone four labeling changes on the basis of case reports suggesting that it can dramatically alter blood glucose levels. ${ }^{54}$ No large-scale studies have examined clinical outcomes related to the dysglycemic effects of outpatient gatifloxacin therapy. Using the health care records of more than 1.4 million Ontario residents 66 years of age or older, we found that gatifloxacin was strongly associated with subsequent hospital care for hypoglycemia and for hyperglycemia. With the exception of a slight increase in the risk of hypoglycemia 
with levofloxacin, these risks were not shared by other fluoroquinolones. Dysglycemic events were not restricted to patients receiving drug treatment for diabetes. The relative absence of dysglycemia in association with the other fluoroquinolone antibiotics is consistent with the findings of previous reports and analyses from post-marketing surveillance in the United States and Cana$\mathrm{da}^{10,12,16}$ and is not suggestive of a class effect for the fluoroquinolones.

It is uncommon for one drug to have directly opposing adverse effects, but clearly possible as evidenced by the dysglycemic effects of pentamidine and the competing thyroid effects of amiodarone. ${ }^{55,56}$ Indeed, the gatifloxacin product monograph describes a post-marketing study of 70 volunteers with type 2 diabetes; in some, hypoglycemia followed by hyperglycemia developed during gatifloxacin therapy. ${ }^{20}$

Severe infections can predispose patients to both hypoglycemia and hyperglycemia, and our findings may reflect the selective use of gatifloxacin in particularly ill patients. However, confounding by indication is an unlikely explanation for our findings, for two reasons. First, we conducted the investigation as a nested case-control study among patients recently treated with antibiotics that have highly similar indications, including other fluoroquinolones that share chemical, mechanistic, and antimicrobial properties with gatifloxacin. Second, although our data do not permit reliable examination of a dose-response relation, the rapid onset, specificity, and magnitude of the association between gatifloxacin use and hypoglycemia (an increase in risk by a factor of more than 4) and hyperglycemia (an increase in risk by a factor of nearly 17) substantially advance the argument for causality.

Our study has several limitations that merit emphasis. Because we relied on records of hospital visits for hypoglycemia and hyperglycemia, we were unable to identify dysglycemic events that did not lead to care in a hospital or emergency department. Many of these events were presumably mild, but others (particularly hypoglycemia) may have resulted in death outside the hospital setting. Overall, our analysis probably underestimates the true occurrence of dysglycemia with all antibiotics, including gatifloxacin. In addition, we had no access to data on blood glucose levels, and we categorized patients as having diabetes on the basis of prescription claims. Some patients may have had diet-controlled or latent diabetes aggravated by illness or antibiotic use.

Some of the clinicians seeing patients in this study may have been familiar with reports of gatifloxacin-associated abnormalities in glucose metabolism, but detection bias cannot explain our findings, because glucose is routinely measured in older patients who seek medical attention in the hospital, particularly those with diabetes. Some covariates (e.g., alcoholism) may not be completely accounted for with the use of diagnostic claims, and we were unable to identify other important factors, such as diet, exercise patterns, and use of nonprescription drugs. Finally, we studied older patients, and whether our findings can be generalized to younger patients is unknown. However, each of these limitations applies equally to all of the antibiotics we studied, and none threaten our conclusion that gatifloxacin treatment, as compared with treatment with other broad-spectrum antibiotics, is associated with a dramatically increased risk of both hypoglycemia and hyperglycemia.

We believe that our findings have important implications for clinical practice. Physicians and pharmacists should be aware of the increased risk of potentially life-threatening glucose abnormalities during gatifloxacin therapy. Patients treated with gatifloxacin should be instructed to seek medical attention if symptoms of hypoglycemia or hyperglycemia develop. Finally, because gatifloxacin offers relatively few therapeutic advantages over alternative antibiotics that confer little or no increased risk of dysglycemia, including other fluoroquinolones, some clinicians may elect to avoid the use of gatifloxacin altogether.

Supported by a postdoctoral Strategic Training Fellowship from the Canadian Institutes for Health Research and a Peterborough K.M. Hunter Fellowship award (both to Dr. Park-Wyllie) as well as by New Investigator Awards (to Drs. Juurlink and Mamdani) and a Clinician-Scientist Award (to Dr. Shah) from the Canadian Institutes for Health Research. Dr. Juurlink was also supported by the University of Toronto Drug Safety Research Group.

Presented in part at the Interscience Conference on Antimicrobial Agents and Chemotherapy, Washington, D.C., December 17, 2005.

Dr. Park-Wyllie reports having received lecture fees from BristolMyers Squibb. Dr. Juurlink reports having received speaker's fees from Sanofi-Aventis, Bristol-Myers Squibb, and Parke-Davis. Dr. Stumpo reports having served on advisory boards for JanssenOrtho, Bristol-Myers Squibb, and Bayer and having received grant support from Bayer. Dr. Dresser reports having served on the advisory boards of Bristol-Myers Squibb, Bayer, and WyethAyerst; having received lecture fees from Sanofi-Aventis and grant support from Wyeth-Ayerst; and having served as an expert witness for Bayer in a Canadian patent dispute. Dr. Low reports having received consulting fees, speaker's fees, and grant sup- 
port from Bristol-Myers Squibb, Ortho-McNeil, and Bayer and having served as an expert witness for Bristol-Myers Squibb. Dr. Mamdani reports having commenced employment with Pfizer in January 2006. No other potential conflict of interest relevant to this article was reported.
We are indebted to Daniel Hackam, Donald Redelmeier, and Matthew Stanbrook for comments on drafts of this manuscript; to Brandon Zagorski for analytical assistance; and to Lina Paolucci for assistance with manuscript preparation.

\section{REFERENCES}

1. Linder JA, Huang ES, Steinman MA Gonzales R, Stafford RS. Fluoroquinolone prescribing in the United States: 1995 to 2002. Am J Med 2005;118:259-68

2. Frothingham R. Quinolone safety and efficacy more important than potency. Emerg Infect Dis 2004;10:156-7.

3. Food and Drug Administration. Temafloxacin P92-16. 1998. (Accessed March 6, 2006, at http://www.fda.gov/bbs/topics NEWS/NEW00279.html.)

4. Rubinstein E. History of quinolone and their side effects. Chemotherapy 2001 47:Suppl 3:3-8, 44-8.

5. Food and Drug Administration. Glaxo Wellcome voluntarily withdraws Raxar (grepafloxacin). 1999. (Accessed March 6, 2006, at http://www.fda.gov/medwatch/ SAFETY/1999/raxar.html.)

6. Ball P. New antibiotics for communityacquired lower respiratory tract infections improved activity at a cost? Int J Antimicrob Agents 2000;16:263-72.

7. Center for Drug Evaluation and Re view, Office of Drug Safety. Questions and answers on trovafloxacin: public health advisory. August 2003. (Accessed March 6, 2006, at http://www.fda.gov/cder/news/ trovan/qa.htm.)

8. Baker SE, Hangii MC. Possible gatifloxacin-induced hypoglycemia. Ann Pharmacother 2002;36:1722-6.

9. Saraya A, Yokokura M, Gonoi T, Seino S. Effects of fluoroquinolones on insulin secretion and beta-cell ATP-sensitive $\mathrm{K}+$ channels. Eur J Pharmacol 2004;497:111-7. 10. Tailor SA, Simor AE, Cornish W, Phillips E, Knowles S, Rachlis A. Analysis of spontaneous report of hypoglycemia and hyperglycemia associated with marketed systemic fluoroquinolones made to the Canadian Adverse Drug Reaction Monitoring Program. Can J Hosp Pharm 2004;57 12-7.

11. Biggs WS. Hypoglycemia and hyperglycemia associated with gatifloxacin use in elderly patients. J Am Board Fam Pract 2003;16:455-7.

12. Frothingham R. Gatifloxacin associated with a 56-fold higher rate of glucose homeostasis abnormalities than comparator quinolones in FDA Spontaneous Reporting Database. In: Program and ab stracts of the 44th Interscience Conference on Antimicrobial Agents and Chemother apy, Washington, D.C., October 30-November 2, 2004. Washington, D.C.: American Society for Microbiology, 2004:19. abstract. 13. Greenberg AL, Decerbo M, Fan J. Gatifloxacin therapy associated with hypo glycemia. Clin Infect Dis 2005;40:1210-1. 14. Khovidhunkit W, Sunthornyothin S.
Hypoglycemia, hyperglycemia, and gatifloxacin. Ann Intern Med 2004;141:969.

15. LeBlanc M, Belanger C, Cossette P. Severe and resistant hypoglycemia associated with concomitant gatifloxacin and glyburide therapy. Pharmacotherapy 2004 24:926-31.

16. Létourneau G, Morrison H, McMorran M. Gatifloxacin: hypoglycemia and hyperglycemia. Can Adverse React News 2003;13(3):1-2.

17. Menzies DJ, Dorsainvil PA, Cunha BA Johnson DH. Severe and persistent hypoglycemia due to gatifloxacin interaction with oral hypoglycemic agents. Am J Med 2002;113:232-4.

18. Arce FC, Bhasin RS, Pasmantier R Severe hyperglycemia during gatifloxacin therapy in patients without diabetes. Endocr Pract 2004;10:40-4.

19. Bhatia V, Bhatia R, Dhindsa S. Gatifloxacin-induced hyperglycemia. Endocr Pract 2004;10:86.

20. Tequin (gatifloxacin). Princeton, N.J.: Bristol-Myers Squibb, 2004 (package insert)

21. Brogan SE, Cahalan MK. Gatifloxacin as a possible cause of serious postoperative hypoglycemia. Anesth Analg 2005;101: 635-6. [Erratum, Anesth Analg 2005;101: 1614.]

22. Cannon CP, Braunwald E, McCabe $\mathrm{CH}$, et al. Antibiotic treatment of Chlamydic pneumoniae after acute coronary syndrome. N Engl J Med 2005;352:1646-54.

23. Donaldson AR, Vandiver JR, Finch CK. Possible gatifloxacin-induced hyperglycemia. Ann Pharmacother 2004;38:602-5.

24. Center for Drug Evaluation and Review. Medical officer review of NDA 21-061 and 21-062: Tequin (gatifloxacin). June 2005. (Accessed March 6, 2006, at http://www fda.gov/cder/foi/nda/99/21061_Tequin. htm.)

25. Frothingham R. Glucose homeostasis abnormalities associated with use of gatifloxacin. Clin Infect Dis 2005;41:1269-76. 26. Happe MR, Mulhall BP, Maydonovitch CL, Holtzmuller KC. Gatifloxacin-induced hyperglycemia. Ann Intern Med 2004;141 968-9.

27. Maeda N, Tamagawa T, Niki I, et al. Increase in insulin release from rat pan creatic islets by quinolone antibiotics. $\mathrm{Br}$ Pharmacol 1996;117:372-6.

28. Ambrose PG, Bhavnani SM, Cirincione BB, Piedmonte M, Grasela TH. Gatifloxacin and the elderly: pharmacokineticpharmacodynamic rationale for a potential age-related dose reduction. J Antimicrob Chemother 2003;52:435-40.

29. Gajjar DA, LaCreta FP, Kollia GD, et al.
Effect of multiple-dose gatifloxacin or ciprofloxacin on glucose homeostasis and insulin production in patients with noninsulin-dependent diabetes mellitus maintained with diet and exercise. Pharmacotherapy 2000;20:76S-86S.

30. Gajjar DA, LaCreta FP, Uderman HD, et al. A dose-escalation study of the safety, tolerability, and pharmacokinetics of intravenous gatifloxacin in healthy adult men. Pharmacotherapy 2000;20:49S-58S. 31. Grasela DM, Lacreta F, Kollia G, Randall D, Stoltz R, Berger S. Lack of effect of multiple-dose gatifloxacin (GAT) on oral glucose tolerance (OGTT), glucose and insulin homeostasis, and glyburide pharmacokinetics (PK) in patients with type II non-insulin-dependent diabetes mellitus (NIDDM). In: Program and abstracts of the 39th Interscience Conference on Antimicrobial Agents and Chemotherapy, San Francisco, September 26-29, 1999. Washington, D.C.: American Society for Microbiology, 1999:11. abstract.

32. Graumlich JF, Habis S, Avelino RR, et al. Hypoglycemia in inpatients after gatifloxacin or levofloxacin therapy: nested case-control study. Pharmacotherapy 2005; 25:1296-302.

33. Mohr JF, McKinnon PS, Peymann PJ Kenton I, Septimus E, Okhuysen PC. A retrospective, comparative evaluation of dysglycemias in hospitalized patients receiving gatifloxacin, levofloxacin, ciprofloxacin, or ceftriaxone. Pharmacotherapy 2005;25:1303-9.

34. Schwarzbard L, Lodise TP, Lomaestro BM, Smith R. Comparison of glucose intolerance (GI) between gatifloxacin (G) and levofloxacin (L) in elderly, hospitalized patients. In: Program and abstracts of the 45th Interscience Conference on Antimicrobial Agents and Chemotherapy, Washington, D.C., December 16-19, 2005. Washington, D.C.: American Society for Microbiology, 2005:463. abstract. 35. Juurlink DN, Mamdani MM, Lee DS, et al. Rates of hyperkalemia after publication of the Randomized Aldactone Evaluation Study. N Engl J Med 2004;351:543-51. 36. Mamdani M, Juurlink DN, Lee DS, et al. Cyclo-oxygenase-2 inhibitors versus non-selective non-steroidal anti-inflammatory drugs and congestive heart failure outcomes in elderly patients: a populationbased cohort study. Lancet 2004;363:1751-

37. Juurlink DN, Mamdani M, Kopp A, Laupacis A, Redelmeier DA. Drug-drug interactions among elderly patients hospitalized for drug toxicity. JAMA 2003;289: 1652-8. 
38. Statistics Canada. Population by sex and age group, by province and territory. 2005. (Accessed March 6, 2006, at http:// www40.statcan.ca/101/cst01/demo31a.

htm.)

39. Levy AR, O'Brien BJ, Sellors C, Grootendorst $\mathrm{P}$, Willison D. Coding accuracy of administrative drug claims in the Ontario Drug Benefit database. Can J Clin Phar macol 2003;10:67-71.

40. Glazier RH, Creatore MI, Agha MM, Steele LS. Socioeconomic misclassification in Ontario's Health Care Registry. Can J Public Health 2003;94:140-3.

41. Alter DA, Austin PC, Naylor CD, Tu JV. Factoring socioeconomic status into car diac performance profiling for hospitals does it matter? Med Care 2002;40:60-7.

42. Alter DA, Iron K, Austin PC, Naylor CD. Socioeconomic status, service pat terns, and perceptions of care among survivors of acute myocardial infarction in Canada. JAMA 2004;291:1100-7.

43. Alter DA, Naylor CD, Austin P, Tu JV. Effects of socioeconomic status on access to invasive cardiac procedures and on mortality after acute myocardial infarction. N Engl J Med 1999;341:1359-67.

44. Ray JG, Mamdani M, Tsuyuki RT, An- derson DR, Yeo EL, Laupacis A. Use of statins and the subsequent development of deep vein thrombosis. Arch Intern Med 2001;161:1405-10.

45. Mamdani MM, Tu K, van Walraven C Austin PC, Naylor CD. Postmenopausal es trogen replacement therapy and increased rates of cholecystectomy and appendectomy. CMAJ 2000;162:1421-4.

46. The international statistical classification of diseases and related health problems, 10th rev. Ottawa: Canadian Institute for Health Information, 2003.

47. Chan JC, Cockram CS, Critchley JA. Drug-induced disorders of glucose metabolism: mechanisms and management. Drug Saf 1996;15:135-57.

48. Pandit MK, Burke J, Gustafson AB, Minocha A, Peiris AN. Drug-induced disorders of glucose tolerance. Ann Intern Med 1993;118:529-39.

49. Schneeweiss S, Maclure M. Use of comorbidity scores for control of confound ing in studies using administrative databases. Int J Epidemiol 2000;29:891-8. 50. Schneeweiss S, Seeger JD, Maclure M, Wang PS, Avorn J, Glynn RJ. Performance of comorbidity scores to control for confounding in epidemiologic studies using claims data. Am J Epidemiol 2001;154: 854-64.

51. Schneeweiss S, Wang PS, Avorn J, Glynn RJ. Improved comorbidity adjustment for predicting mortality in Medicare populations. Health Serv Res 2003;38:110320.

52. Schneeweiss S, Wang PS, Avorn J, Maclure M, Levin R, Glynn RJ. Consistency of performance ranking of comorbidity adjustment scores in Canadian and U.S. utilization data. J Gen Intern Med 2004; 19:444-50

53. Altman DG, Bland JM. Interaction revisited: the difference between two estimates. BMJ 2003;326:219.

54. Center for Drug Evaluation and Review, Office of Drug Safety. Medical product safety information. (Accessed March 6, 2006, at http://www.fda.gov/medwatch/ safety.htm.)

55. Assan R, Assan D, Delaby J, Debussche $\mathrm{X}$, Toublanc M. Pentamidine-induced dysglycaemia: experimental models in the rat. Diabete Metab 1993;19:262-72.

56. Basaria S, Cooper DS. Amiodarone and the thyroid. Am J Med 2005;118:706-14.

Copyright (c) 2006 Massachusetts Medical Society.

CLINICAL TRIAL REGISTRATION

The Journal encourages investigators to register their clinical trials in a public trials registry. The members of the International Committee of Medical Journal Editors plan to consider clinical trials for publication only if they have been registered (see N Engl J Med 2004;351:1250-1).

The National Library of Medicine's www.clinicaltrials.gov is a free registry, open to all investigators, that meets the committee's requirements. 